\title{
Saving Elephants in Africa - Concept to Reality through Experiential Engineering Design
}

\author{
R.E. Gorga* and J.S. Jur* \\ * Department of Textile Engineering, Chemistry \& Science \\ North Carolina State University
}

\begin{abstract}
The purpose of this work is to provide undergraduate seniors in engineering 1) the opportunity to work on an industry/externally sponsored project and 2) provide an outside the classroom learning experience. Here we discuss each of these aspects as it relates to a single project, specifically working to save African elephants from unnecessary slaughter. The main results are that 1) industry sponsor commitment to the project is the number driver for overall success of the project and 2) an inthe-field educational experience is invaluable for the students to learn the real world pressures of time constraints and developing real-time contingency plans to successfully complete project goals. In conclusion, we discuss how an external sponsor, committed to interacting with the team and an "outside the classroom" learning experience coupled with good mentoring from the faculty provide an experience that closely parallels a real-life work experience for the students.
\end{abstract}

Keywords: Engineering Design; Undergraduate Education; Industry-Student Interaction; Project-based Learning; Outside-the-classroom learning

\section{Introduction}

Senior Design Capstone Course - The Senior Design capstone course serves as the final stage in the student's undergraduate degree to apply their skills to unique problems. Student entering this capstone course in the Department of Textile Engineering, Chemistry and Science (TECS) at North Carolina State University will have already gained valuable expertise in engineering fundamentals, information systems, medical textiles, product development, supply chain management, and consumer behaviour. The Senior Design capstone course provides students the opportunity to work with industry to creatively synthesize solutions to relevant problems, that is, the focus is on experiential learning as described by Kolb (1984). The students work on teams to solve technical problems, study commercialization processes, utilize project management tools, think globally, understand/develop intellectual property and apply patent mapping principles. Students in the TECS program are expected to graduate with the skills necessary to conceive (design and create), specify, implement, test, produce, and market complex engineering systems (see Fig. 1). Often, teaming with other department senior design course (such as this project outlined later in this paper) offers an experience that is similar to reality after college. These other senior design courses have parallel objectives to the TECS program.

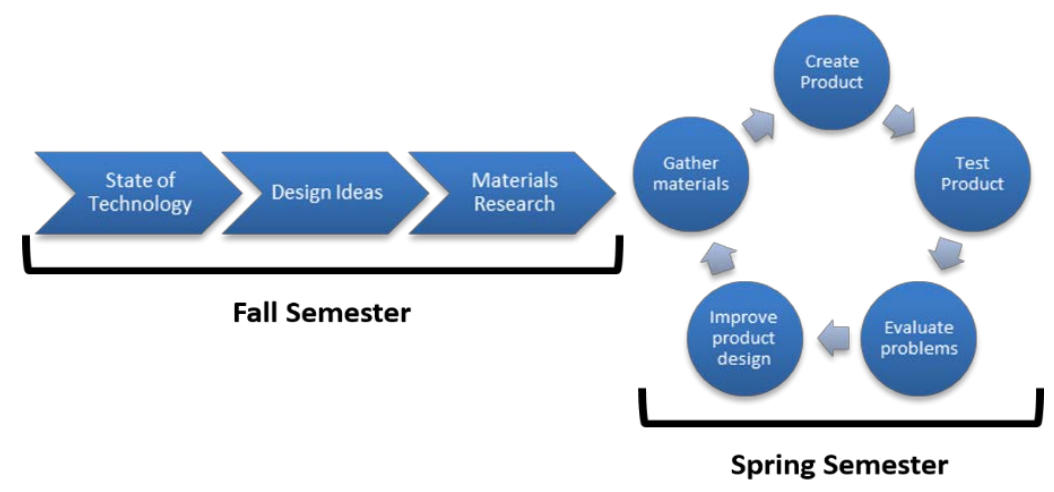

Figure 1. Overarching course paradigms for the fall and spring semesters. 
Industry Sponsors - Project stakeholders from industry sponsor and the faculty mentors (Drs. Jur and Gorga) guide the student team through the engineering design process to develop an innovative product that meets the criteria and constraints of the project definition. In the past two years, project sponsors have included: HanesBrand, Army Research Office, Nike, Johnson Controls, Limited Brands, Adidas, Hunter Safety Systems, Under Armour, Secant Medical, Porticos, and Firestone (see Fig. 2). Example final posters and student testimonials may be found online at: http://tx.ncsu.edu/tecs/acdemics/senior-design/.

Experience has shown that a project's success has very little to do with the project topic or the "name" of the company, but is strongly correlated to the commitment the sponsor has to interacting with the student team. If the sponsor has a strong commitment to communicating (providing feedback, answering questions, and generally being responsive to the team) the project has the highest probability for being successful. Therefore the faculty mentors have developed screening tools (to aid in sponsor selection) and provided guidelines and guidance to the sponsors (once selected) to help ensure a successful sponsor-team interaction.

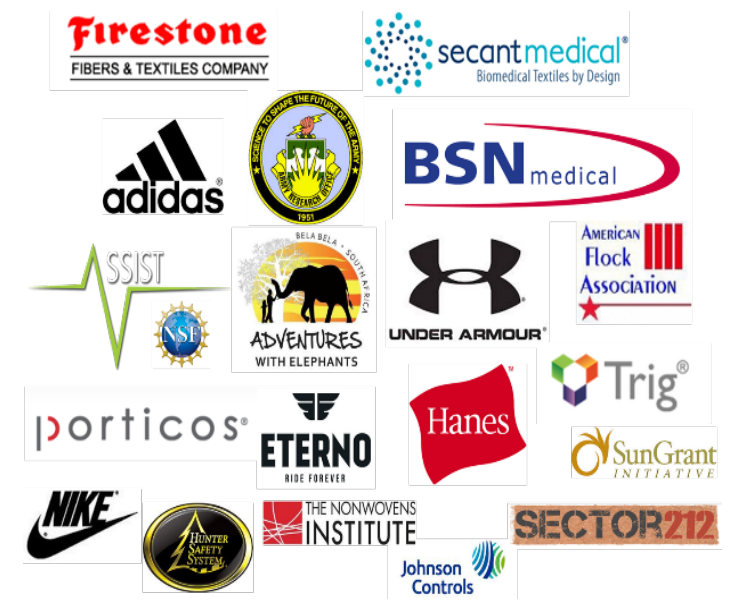

The most rewarding and educational aspect of the course for the student and sponsor is their mutual interaction. Expectations for the sponsor mentor include:

$>$ Regular meetings with team

$>$ Assist in defining project scope

$>$ Provide specific project feedback

$>$ Provide technical mentoring \& feedback on their deliverables

$>$ Provide coaching to help the student team reach the best solutions...it is important for the sponsor mentor not to tell the team exactly what to do!

Figure 2. Examples of industry sponsors over the last two academic years with an excerpt taken from our sponsorship solicitation (and the sponsor contract). In this period we have mentored 31 project teams, encompassing 98 undergraduate students in their last year of academic study.

\section{Teaching Pedagogy}

The teaching pedagogies employed in this particular project include both experiential learning (Kolb, 1984) and outside the classroom experiences, as discussed by Kuh (1994). This project is unique in that it incorporates both pedagogies. While every senior design project does focus on experiential learning, not everyone has as strong an outside the classroom component. However, our classroom is unique in that the focus is on a problem based learning platform (Savery and Duffy, 1994) and is therefore not a "traditional" classroom experience.

\section{Experiential Example: Collar for Elephant Monitoring and Feedback}



Figure 3. The "outside the classroom" classroom. This is the location where the collar was placed on the elephant, evaluated, and further iterations of redesign and testing occurred over the week long event. 
Background - The need for a keeping elephants out of villages is immediate. Elephants are getting killed and injured just because they go into areas in which they do not belong. Ensuring elephants stay out of villages keeps the villagers safe from their crops being destroyed, their houses getting damaged, and their water sources from being eliminated. The human-elephant conflict will only increase until preventative measures are made to allow humans and elephants to coexist without difficulty. The question posed by Sean Hensman (Director, Adventures with Elephants) was: "Can an innovative self-power collar be fabricated that provides non-harmful feedback to deter elephants from a designated area?" In response to this request, our team developed concepts for integrating nature-inspired feedback (sound and vibration) into the collar that allows for informed deterrence of the elephant into unwanted locations.

Existing technology for an elephant collars have the sole purpose of geotracking. Initial efforts by our team were to re-define an elephant collar with the following criteria and constraints:

1) The collar must be self-powered for extended useable lifetime of the animal in the wild. (The current battery life is short, often 1 month or less, resulting in the need to charge the battery which requires animal tranquilization.) A self-powering strategy is minimally invasive and the lifetime goal is 5-8 years.

2) Location tracking of the elephant must be included. The African landscape requires special protocols for communication between the collar and a base station.

3) Nature-inspired feedback mechanisms should be integrated into the collar. Protection of the elephant is paramount!

4) The collar must be 'elephant' and 'Africa' durable, as well as be of reduced burden as compared to the current collar structures, since the African environment is already tough enough on the elephant.

Testing - A major result of the senior design project was a field analysis (see Fig. 3) conducted at Adventures with Elephants in March of 2014. This field experience is in line with the importance of outside the classroom experiences, as described by Kuh (1994). Adventures with Elephants is a range, directed by Sean Hensman, that provides shelter for a group of five elephants that have previously faced life threatening circumstances. To support the facility, Adventures with Elephants provides positive human-elephant interactions that teaches humans about the elephants. More information can be found here: www.adventureswithelephants.co.za. The following field tests were performed using two collars and additional verification testing equipment.

1) The first collar, which was designed to primarily test packaging durability, was given a 24 hour stress by placing the collar on the bull elephant. From this test we observed behavior of the elephant's reaction to the collar and the elements that the collar would endure in a typical day. Figure 4 provides images of the application of the collar upon Chisuru and the durability testing.

2) The first collar, which was designed to primarily test packaging durability, was given a 24 hour stress by placing the collar on the bull elephant. From this test we observed behavior of the elephant's reaction to the collar and the elements that the collar would endure in a typical day. 


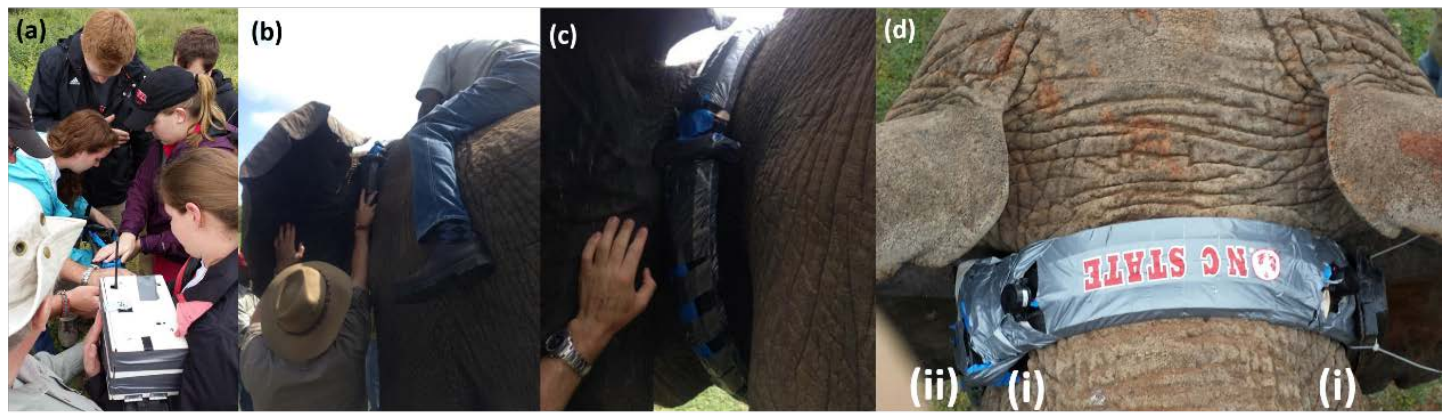

Figure 4. (a) Undergraduate student team performing one last verification test of the electronics. The electronics were held in a white box located at the bottom of the image. The antenna for remote control of the buzz and vibration can be observed sticking through the box. (b) Application of the collar onto Chisuru. (c) The collar in place. (d) Top view of the collar showing the locations of the speakers for the buzz feedback (i) located behind each ear and the motor used for vibration (ii) located on the side of the neck. The location of the motor can also be seen in (c).

3) A second collar, not constructed for durability testing, incorporated vibration and soundbased feedback mechanisms, as shown in Figure 4. The vibration feedback was design to the simulate ant or insect movement, while the sound (or buzz) was design to simulate bees. To test these feedback mechanisms, a remote activation of the collar was employed. The collar was again placed on the bull elephant and was subsequently allowed to go toward a field that contained a pile of apples. Perimeter zones designated at $\sim 50$ and $\sim 25$ meters away from apples were used for activation of the sound and vibration, respectively. A diagram and results of the initial experiment are shown in Figure 5. Our collar showed that upon activation of the vibration, Chisuru stopped abruptly (Fig. 5(c)), turned away from apple pile, and walked back to the rest of the pack. Moreover, Chisuru did not approach the area for a period of $30+$ days after our departure.

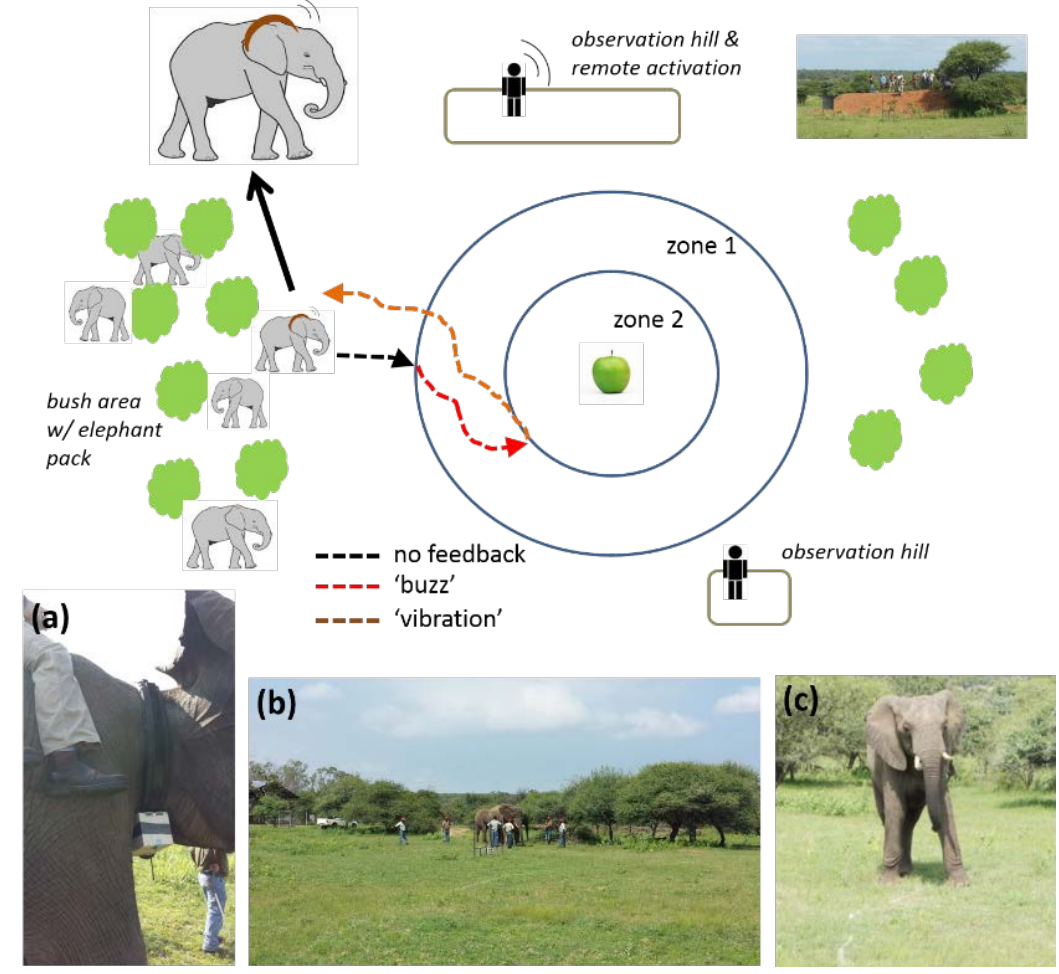

Figure 5. Diagram of the testing scenario used to verify the feedback hypothesis. When Chisuru heard the buzz sound, he stopped briefly before proceeding to the apples. When he felt the vibration, he stopped and returned to the pack in the bush adjacent to the field. The bottom panels show (a) Chisuru prior to the test, (b) the field test site, and (c) Chisuru's initial reaction when the vibration was initiated. 
4) The efficiency of the solar cells were evaluated at various conditions, including sunlight and time of day to determine a prospective power harvesting capability and number of solar cells required to support the collar.

5) Two prospective GPS devices were tested and verified for signal strength at 8+ strategic locations at the $25 \mathrm{~km}^{2}$ Adventures with Elephants range. This included evaluation of a tracking software tested on site.

Upon arrival back to NC State, the teams implemented solutions to the preceding design challenges in a new prototype iteration of the collar, with a focus on reduced weight and improved surface smoothness. In addition, a first draft of an electronics manual was written. This prototype, while not solving all of the challenges, provides a material roadmap for methods to improve the collar. These improvements are currently underway in a second year of the project.

\section{Senior Design Capstone Outcomes:}

\section{Industry and Education Relationship -}

$>$ Potential projects are pre-screened by the instructors prior to submission. Often, the project scope is too broad or is outside of the focus of the course. While open-ended questions are sought, parameters need to be set so that there is a tangible 'final product' at the end of the academic year.

Setting expectations for the industry sponsors and reiterating these expectations early in the project is essential to inspire and motivate the industry sponsor. These expectations include a single direct point of contact for the students and providing internal company resources to help ensure the students success.

$>$ While the project topic is provided by the industry sponsor, the details of the project (criteria and constraints) are developed by the students and mutually agreed upon with the sponsor to develop mutual expectations.

$>$ A team contract is developed and approved by the sponsor and faculty advisors, which includes how the teams will report to the sponsor (email, video conference, conference call) and how frequently (weekly, bi-weekly). The contract also identifies how the team will operate and deal with internal conflict.

> From the viewpoint of the sponsor, often the student team is an indirect employee of the company. This helps the students feel integrated into part of the company culture.

$>$ Intellectual property rights can be the biggest deterrent for a potential industry sponsor to work with a senior design program. At NC State, undergraduate students retain their individual rights outside of the university and may independently sign non-disclosure agreements with the sponsor. This provides an important lesson on how to protect individual rights and retain ownership of intellectual property. Further, many students file patent disclosures and learn how the patenting process works.

$>$ Year by year, we have grown in size and expertise. We encourage a donation of $\$ 10,000$ USD to sponsor a project, which is adjusted based on the scope of the project and the size of the company. We will typically lower the cost for smaller, in-state companies. This monetary investment by the sponsor provides a budgetary foundation for the students and teaches them to operate within a frame work with limited financial resources.

$>$ Two-directional feedback between the sponsor and the faculty mentors is critical for developing strategies in team and project issues. A mutual respect from all parties is necessary for this to be effective. 


\section{Experiences Outside the Classroom -}

One of the issues that is most apparent to the students is the real world time constraints of being in the field. The team only has a finite period of time to achieve its goals, with a very real (and physical) deadline.

Students also need to learn to deal with unforeseen issues and must learn to be adaptable in how to solve these problems and work with the resources available in the moment. Students learn how to develop "in the moment" contingency plans to move forward.

The faculty mentors need to set expectations high. Student teams will rise to the challenge!

Students experience working in a high stress environment (real life situations create different stressors than classroom stressors). This experience prepares them for stressors similar to what they will face in the workplace.

$>$ Global perspective and awareness is difficult to teach in the classroom, but can be easily communicated through an on-site experience. The students gained an appreciation for the gentle character, physical power, and high intelligence of the elephant and the endangerment they face through human conflict that other senior design projects would not have otherwise provided. This inspiration quickly spread across the university and beyond as the team was invited to speak to high school summer programs regarding their experience. A story on the project featured on NC State's website (https://news.ncsu.edu/2014/10/elephant-collar/).

\section{Conclusions}

The main results are that 1 ) industry sponsor commitment to the project is the number driver for overall success of the project and 2) an outside the classroom educational experience is invaluable for the students to learn the real world pressures of time constraints and developing real-time contingency plans to successfully complete project goals. In conclusion, we discuss how an external sponsor, committed to interacting with the team and an "in the field" learning experience coupled with good mentoring from the faculty provide an experience that closely parallels a real-life work experience for the students.

\section{References}

Kolb, D. A. (1984). Experiential learning: experience as the source of learning and development. Englewood Cliffs, NJ: Prentice Hall.

Kuh, G. D. (1994). Student Learning Outside the Classroom: Transcending Artificial Boundaries. ERIC Digest.

Savery, J. R., and Duffy, T. M. (1995). Problem based learning: An instructional model and its constructivist framework. Educational technology, 35(5), 31-38. 